EPRA International Journal of Economic and Business Review-Peer Reviewed Journal

Volume - 9, Issue - 4, April 2021 | e-ISSN: 2347 - 9671| p- ISSN: 2349 - 0187

\title{
EXPLORING MULTIDIMENSIONAL PERSPECTIVE OF POVERTY AMONG THE RURAL PANGALS IN MANIPUR: A CASE STUDY
}

\begin{tabular}{|c|c|}
\hline $\begin{array}{c}\text { Tampakmayum Alan } \\
\text { Mustofa }^{1}\end{array}$ & $\begin{array}{c}{ }^{1} \text { Ph.D scholar and ICSSR fellow in The Centre for } \\
\text { North East Studies and Policy Research, Jamia } \\
\text { Millia Islamia, New Delhi }\end{array}$ \\
\hline $\begin{array}{l}\text { Mohd Himat Ali } \\
\text { Tampakmayum }\end{array}$ & $\begin{array}{c}{ }^{2} \text { Ph.D scholar in The Centre for North East Studies } \\
\text { and Policy Research, Jamia Millia Islamia, } \\
\text { New Delhi }\end{array}$ \\
\hline Md Qamar Azam ${ }^{3}$ & $\begin{array}{c}{ }^{3} \text { Ph.D scholar in Economics Department, Jamia } \\
\text { Millia Islamia, New Delhi }\end{array}$ \\
\hline
\end{tabular}

\begin{abstract}
DOI No: 10.36713/epra6666

Article DOI URL: https://doi.org/10.36713/epra6666

This paper analyses poverty among the rural Pangals in Manipur on a Multidimensional perspective. For the analysis, Borayangbi Gram Panchayat where Pangal community settle in large number is selected. By utilizing a field survey data conducted during the first quarter of 2019 the Multidimensional Poverty of Borayangbi Gram Panchayat is estimated. Borayangbi is a remote village located in the southern part of Imphal Valley under Moirang Sub-Division in Bishnupur District, Manipur. The village is worthwhile to study its level of poverty and deprivation as there are limited studies in this area. Multidimensional Poverty Index captures the simultaneous deprivations of each person in different households. The methodology used in the study is developed by Alkire and Foster and involves three dimensions: health, education and living standard. Additional indicators are also used to suit the study of the area concerned. This methodology enhances the better understanding of poverty and deprivation of the concern village. A stratified random sampling technique was used to conduct the survey of 100 households in the village. In the study, it is found that the largest contribution of deprivation is the dimension of living standard. People in the village experience maximum deprivation in the indicators of cooking fuels and safe drinking water. The results and information can be used to design policy perspective of the village and help in targeting poverty alleviation program.
\end{abstract}

KEYWORDS: Multidimensional Poverty Index, Alkire Foster Method, Borayangbi, Pangals 


\section{INTRODUCTION}

The idea of Multidimensional Poverty has been discussing widely over the last two decades among the policy makers and researchers. The capability approaches of Amartya Sen, Millennium Development Goals and different strategies of poverty measures in different countries have led to the discussion of multiple deprivation of poor people in this world. The income poverty alone could not provide sufficient data regarding the deprivation in different dimensions (Alkire and Foster, 2007). Poverty refers to be hungry, inadequate shelter and clothing, no one care for illness, illiterate, etc. The mixed characteristic of poverty is lack of resources through which descent standard of living cannot be reached. (Philip, D and Rayhan, M. I, 2004). The Oxford Poverty and Human Development Initiative (OPHI) and United Nations Development Programme developed the Global Multidimensional Poverty Index (MPI) in 2010. The perception of multidimensional in poverty has suppressed the traditional notion of poverty in terms of income or consumption/expenditure deprivations (Alkire, S. and Foster, J. 2011). MPI captures the poverty nature and its intensity at the individual and household level, and the deprived people in multiple dimensions (OPHI, 2010). It can be used to measure poverty at different strata of the society. It is often used to measure the deprivation in the individual and household base on the level of country, state, region or group of people. In 2016, around 1.6 billion people are living in multidimensional poverty in 102 countries (OPHI, 2017) which is the $30 \%$ of their total population. One third of the world's poor is in India. According to the report of OPHI, 53.80 percent people are multidimensional poor in 2016, and out of total 1.6 billion people globally, 440 million poor people are living in poorest eight major Indian states of Bihar, Chhattisgarh, Jharkhand, Madhya Pradesh, Odisha, Rajasthan, Uttar Pradesh and West Bengal (OPHI, 2017).

This paper analyses Multidimensional perspective of poverty among the rural Pangals in Manipur. Pangals are the minority ethnic community of Manipur. They follow the Islamic religion. They have been living in peaceful coexistence with the majority community, Meitei and other communities since then. Most of their culture and traditions have been adopted, assimilated, and intermixed with the local Meitei community. According to the 2011 census, out of the total population of $28,55,794$, the share of Pangal population is $2,39,836$ persons, comprising 8.39 percent of the total population. Small in number, they reside in close contiguity with the Meiteis, the major community and other smaller communities in the Imphal valley and in the small valley (Jiribam), located in the Barak valley, an area that together comprised 10 percent of the total land area of the state. In terms of concentration of Pangal population in Manipur, in 2011 census, 96 percent of the Pangals are settled in the four valley districts. Thoubal district has the highest concentration of Pangal population constituting about 45 percent of their total population. According to the Socio-Economic Survey of Meitei-Pangal, 2004, 80 percent of Pangal population settle in rural areas. In terms of age group, about 42 percent of their total population is in the age group of $0-14$. It indicates a high birth rate among the Pangals in Manipur. The employment status also shows a grim picture. In 2004, only 24.14 percent of their total population are employed according to the principal usual activities' status. They have the highest percentage of workers who are in the lowest wage group both in the rural and urban areas. Their economy is largely of agrarian base primarily geared towards subsistence than profit generation. Large number of people are self-employed with small proportions engaged in Government jobs.

\section{LITERATURE REVIEW}

Azevedo and Robles (2013) analyse multidimensional poverty and conclude that this method helps in the selection of households having children who are most deprived in the dimensions. Jayaraj and Subramanian (2010) also analyse multidimensional poverty using family headcount indices based on the individual deprivations using National Family Health Survey. The study concludes with a significant result that there was a decline in multidimensional poverty between 1991-92 to 2005-06.

National Statistics Bureau (2014) report highlights Bhutan's national Multidimensional Poverty Index (MPI) based on the Alkire Foster methodology. It has the three dimensions of health, education, and standard of living used in the global MPI. Emphasizing the Bhutan's priorities, 13 indicators are used here. Two indicators are used for each of the health dimension (Child Mortality and Food Security) and the education dimension (School Attendance and Schooling). In standard of living dimensions nine indicators are used (Cooking Fuel, Sanitation, Electricity, Water, Road, Housing, Asset, Land and Livestock). According to different household sizes, there is not much variation in the proportion of poor. The poverty rate is higher in the household having nine or more members, but they represent just nine percent of the population.

Dehury \& Mohanty (2015) measure multidimensional poverty using unit data from the Indian Human Development Survey (IHDS), 2011-12, and decompose the multidimensional poverty dynamics in 82 natural regions of India. It is measured in the dimensions of health, knowledge, income, employment 
and household environment with ten indicators by using Alkire-Foster methodology.

Alkire and Santos (2010) give the insights of multidimensional poverty index. It is very useful in identifying the most vulnerable people in such a way that it brings out the aspects where they are deprived.

Alkire and Seth (2012) explain that the BPLtargeting methodology in India is a close approximation to the standard multidimensional poverty measure.

Alkire and Seth (2013) analyse India's performance in multidimensional poverty between 1999 and 2006 using an adaptation of the Multidimensional Poverty Index (MPI). They find that nationally, multidimensional poverty has fallen in India between 1999 and 2006.

Alkire \& Roche (2011) highlight a new approach to child poverty measurement which include child poverty. The Alkire and Foster method in this paper, considers the intensity of each child's poverty. Once children are identified as poor, the measures aggregate information on poor children's deprivations in a way that can be broken as poor. The resulting measures takes into account the breadth, depth or severity of dimensions of child poverty.

Alkire, et al., (2013), discuss about the indices of multidimensional poverty which measures both the joint incidence of multiple deprivations and their chronicity. They adopted a new approach to the measurement of chronic multidimensional poverty. It depends on the counting approach of Alkire and Foster (2011) for the measurement of multidimensional poverty in each time period; and then on the duration approach of Foster (2011) for the measurement of multidimensional poverty persistence across time

\section{DATA, SAMPLING DESIGN AND METHODOLOGY DATA AND SAMPLING DESIGN}

This study is completely based on the primary data which were collected from the field survey conducted during the first quarter of 2019 at Borayangbi village in Manipur which is around 25 kilometres far away from capital city Imphal. It is a remote village under Moirang sub division in Bishnupur District of Manipur. The village is worthwhile to study its level of poverty and deprivation as there are limited studies in this area. Pangals settle in large number in this village. Majority of the population is under Below Poverty Line (BPL). The village has three parts namely Awang leikai, Thongkha makha leikai, Khunjao Pali and Thoubal leikai. Keeping in mind each part of the village is proportionately represented, 25 households were randomly selected from each part. In total, 100 sample households were selected by following the stratified random sampling technique with household as the unit of analysis. A well-prepared questionnaire comprising the questions and information related to the study were administered through an adult member of the randomly selected household for the collection of data.

\section{METHODOLOGY}

Sabina Alkire and James Foster created a method for calculating multidimensional poverty. This method identifies the poor along with the intensity of deprivation they suffer.

The step by step procedure of Alkire and Foster $(2007,2011)$ methodology is explained below.

1. The source of data must be from the same source. The information of the household or individual should be from the same survey.

2. One can choose the unit of analysis as individual or household based on the types of study. The present study is based on the household survey.

3. The selection of dimensions and indicators is the next step of the procedure. The Global MPI has three dimensions and ten indicators. One can choose the number of dimensions and indicators according to the best suitable of their study. The present study has three dimensions and fourteen indicators.

4. The MPI measures require a deprivation cut-off for each indicator. It is noted as $Z_{i}, i$ is the individual or household. Indicators are denoted by $x_{i}$. If $x_{i}<z_{i}$, then the individual or household is considered deprived. Usually, the deprivation cut-off is based on MDG and SDG guidelines. It may also be set according to the national priorities and culture of the region. The present study follows the same.

5. The next step is to define the weight of each dimension and indicator. In the present study, the weight of each dimension is equally weighted at $1 / 3$. The corresponding indicators are also weighted equally such as two indicators of education are weighted at $1 / 6$; three indicators of health are weighted equally at $1 / 9$ and nine indicators of health are also weighted equally at $1 / 27$. So, the sum of the weights of the total indicators is 1 .

6. Each individual or household is assigned a deprivation score according to their deprivation in the indicators. It is calculated by taking a weighted sum of deprivations and it should be between 0 and 1 . When the individual or household is deprived in all the indicators, then the score is 1 and if they are not deprived in all the indicators, then the score is 0 . Mathematically,

$$
c_{i}=W_{1} I_{1}+W_{2} I_{2}+\ldots \ldots+W_{n} I_{n}
$$


Where, $I_{i}=1$ if the individual or household is deprived and $I_{i}=0$ if the individual or household is non-deprived. And, $w_{i}$ is the weight of the indicator $i$. Also $\sum W_{i}=1$.

7. The next step is the poverty cut-off. It is the share of deprivations an individual or household has for considering as poor. It is represented by $k$. If $c_{i} \geq k$ an individual or household is poor. In the present study, the household is poor, if the deprivation score is higher than or equal to $1 / 3$. For the household whose deprivation score is less than $1 / 3$, it is replaced by 0 , which is called as censoring.

8. Lastly, the MPI is computed. It is the combination of Incidence of Poverty or Multidimensional Headcount Ratio ( $H$ ), which is the proportion of population facing a multiple deprivation and Intensity of Poverty (A), which is the average proportion of deprivation.

$$
H=q / n
$$

Where, $q$ is the number of people who are MPI poor and $n$ is the total population

$$
A=\sum c_{i}(k) / q
$$

Where, $c_{i}(k)$ censored headcount ratio of individual or household $i$ and $q$ is the number of MPI poor population.

Finally, MPI is the product of incidence of poverty and intensity of poverty:

$$
\mathrm{MPI}=H \times A
$$

\section{DECOMPOSITION BY INDICATORS}

When indicators are decomposed, we can obtain the censored headcount ratio and the contribution of deprivation in each indicator. Firstly, the censored head count ratio is calculated with the number of poor people in the particular indicator divided by the total population.

$$
\mathrm{MPI}={ }_{W_{1}} \mathrm{CH}_{1}+{ }_{W_{2}} \mathrm{CH}_{2}+\ldots .+w_{\mathrm{n}} \mathrm{CH}_{\mathrm{n}}
$$

Here, $W_{i}$ is the weight of each indicator, $\mathrm{CH}_{\mathrm{i}}$ is the Censored headcount ratio of each indicator Secondly, we can obtain the contribution of each indicator to the overall MPI. Censored headcount ratio is to be multiplied by the weights of each indicator and then, divided by overall MPI. The result obtained is the MPI of each indicator.

Contribution of each indicator to the overall MPI =

$$
\left(W_{i} \mathrm{CH}_{\mathrm{i}} / \mathrm{MPI}\right) \times 100
$$

\section{DIMENSIONS AND INDICATORS}

The MPI in this study is composed of three dimensions with 14 indicators. Indicators are made to ensure that they are least correlated to each other. A household is considered multidimensional poor if it is deprived in at least one third of the weighted indicators. The following are the indicators used for computing MPI:
1. Education: Education is one of the most important dimensions of MPI. It is also an indicator of human development. The present study consists of two indicators. They are weighted equally at $1 / 6$

- Years of schooling. The household is deprived if no member in the household has completed five years of schooling. It acts as a proxy for knowledge and understanding of the household members. The cut-off for this indicator is at least one member of the household has completed five years of schooling.

- $\quad$ Child School attendance: The household is deprived if any school age child of age 6-14 is not enrolled in school. It also indicates the drop-out rate of school aged child.

2. Health: Health is another important dimension of MPI. Deprivation in this dimension consists of three indicators which are weighted equally at $1 / 9$.

- Child Malnutrition: This indicator gives the information for children of age $0-5$ years of age to determine if they are undernourished. They were identified with the anthropometric measures and the reference from National Centre for Health Statistics (NCHS).

- Female Malnutrition: This indicator also gives the information of undernourished in female adult of reproductive age (1549). It is the Body Mass Index (BMI). A female adult is considered to be undernourished if she has a BMI lower than $18.5 \mathrm{k} / \mathrm{m}^{2}$.

- Child Mortality. The household is considered deprived if any child death (of any age) has occurred in the household within the five-years period preceding the survey.

3. Standard of Living: It consists of nine indicators weighted equally at $1 / 27$. It consists of indicators based on MDGs and SDGs guidelines. The other non MDG and SDG indicators also provide information of the quality of housing which is meant for standard of living of the household.

- House Possession: The household is deprived if there is no own house.

- Floor. Deprivation is considered if the household has a dirt, sand or dung floor.

- Kitchen: If there is no separate kitchen, then the household is considered deprived. 
- Persons per Room: The household is deprived if there is more than two persons per room.

- Sanitation: If the household does not have improved sanitation facility, or shared with other households, then it is considered deprived.

- Electricity. The household is deprived if there is no electricity connection.

- Cooking Fuels: The household is deprived in cooking fuels if dung, charcoal or wood are used.
- Drinking Water: If the household does not access to water sources like public tap, hand pump, protected well, rainwater within a distance of 30 minutes walking distance (round trip), then it is considered deprived.

- Consumer Durables: The household is considered deprived if it does not own more than one radio, TV, mobile phone, refrigerator, washing machine, computer, and does not own at least one (car, bike, motorcycle, auto rickshaw, bus, truck).

Table 1. Multidimensional Poverty Measures: Dimensions, Indicators,

Deprivation cut-off and Relative Weight.

\begin{tabular}{|c|c|c|c|}
\hline $\begin{array}{l}\text { Dimensions of } \\
\text { Poverty }\end{array}$ & Indicators & Deprived if & Weight \\
\hline \multirow[b]{2}{*}{ Education } & Years of Schooling & $\begin{array}{l}\text { No household member } \\
\text { has five years of } \\
\text { schooling }\end{array}$ & $1 / 6$ \\
\hline & $\begin{array}{l}\text { Child School } \\
\text { Attendance }\end{array}$ & $\begin{array}{l}\text { At least one school- age } \\
\text { child not enrolled (6- } \\
14 \text { ) in school }\end{array}$ & $1 / 6$ \\
\hline \multirow{3}{*}{ Health } & Child Undernourished & $\begin{array}{l}\text { Any child is } \\
\text { malnourished }\end{array}$ & $1 / 9$ \\
\hline & $\begin{array}{c}\text { Female } \\
\text { Undernourished }\end{array}$ & $\begin{array}{l}\text { Any female of } \\
\text { reproductive-aged is } \\
\text { malnourished }\end{array}$ & $1 / 9$ \\
\hline & Child Mortality & $\begin{array}{l}\text { Any child of aged }(0-5) \\
\text { has died in the family }\end{array}$ & $1 / 9$ \\
\hline \multirow{8}{*}{ Living Standard } & House Possession & $\begin{array}{c}\text { The household has no } \\
\text { own house }\end{array}$ & $1 / 27$ \\
\hline & Floor & $\begin{array}{l}\text { The household has dirt, } \\
\text { sand or dung floor }\end{array}$ & $1 / 27$ \\
\hline & Kitchen & $\begin{array}{c}\text { The household has no } \\
\text { separate kitchen }\end{array}$ & $1 / 27$ \\
\hline & Persons Per Room & $\begin{array}{l}\text { The household has } \\
\text { more than } 2 \text { persons } \\
\text { per room }\end{array}$ & $1 / 27$ \\
\hline & Toilet & $\begin{array}{l}\text { The household has no } \\
\text { improved sanitation } \\
\text { facility or it is improved } \\
\text { but shared }\end{array}$ & $1 / 27$ \\
\hline & Electricity & $\begin{array}{c}\text { The household has no } \\
\text { electricity }\end{array}$ & $1 / 27$ \\
\hline & Cooking Fuel & $\begin{array}{l}\text { The household uses } \\
\text { dung, wood or charcoal } \\
\text { for cooking }\end{array}$ & $1 / 27$ \\
\hline & Drinking Water & $\begin{array}{l}\text { The household does not } \\
\text { access to safe drinking } \\
\text { water facility }\end{array}$ & $1 / 27$ \\
\hline
\end{tabular}




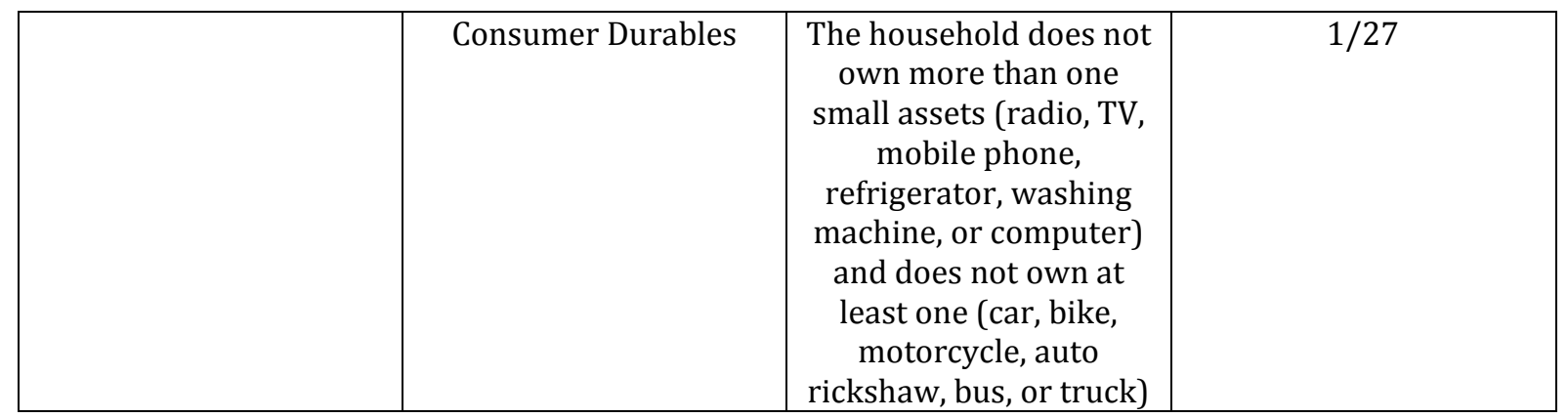

\section{RESULTS AND DISCUSSIONS}

Multidimensional Poverty Index of the village Borayangbi comes out as 0.208 . The poverty incidence,
Multidimensional Headcount Ratio $(\mathrm{H})$ of the village is $48.8 \%$. Moreover, the Intensity of Poverty (A) of the village comes out as $42.8 \%$.

Table 2: Multidimensional Poverty Rates.

\begin{tabular}{|c|c|c|c|}
\hline & MPI & H & A \\
\hline Borayangbi & 0.208 & $48.8 \%$ & $42.8 \%$ \\
\hline
\end{tabular}

\section{CENSORED HEADCOUNT RATIO}

The censored headcount ratio is the proportion of people who are MPI poor and deprived in each indicator. It is different from the raw headcount ratio as it considers only those are poor, ignoring the deprivation of non-poor. Figure. 1 represents the percentage or proportion of people in households of the village who are MPI poor and are also deprived in each indicator. The figure shows that $96.3 \%$ of the population are MPI poor and are also deprived in safe and clean drinking water. It is because the majority of the households do not have safe drinking water facilities. The second most deprived indicator is cooking fuel which is $85 \%$ of the total population. The reason behind it is that majority of the households use firewood as the cooking fuel which are very harmful to health. $51 \%$ of the population in the village are MPI poor and do not have adequate assets to meet the standard of living. Also, $45.4 \%$ of the household population have dirt floor and they are

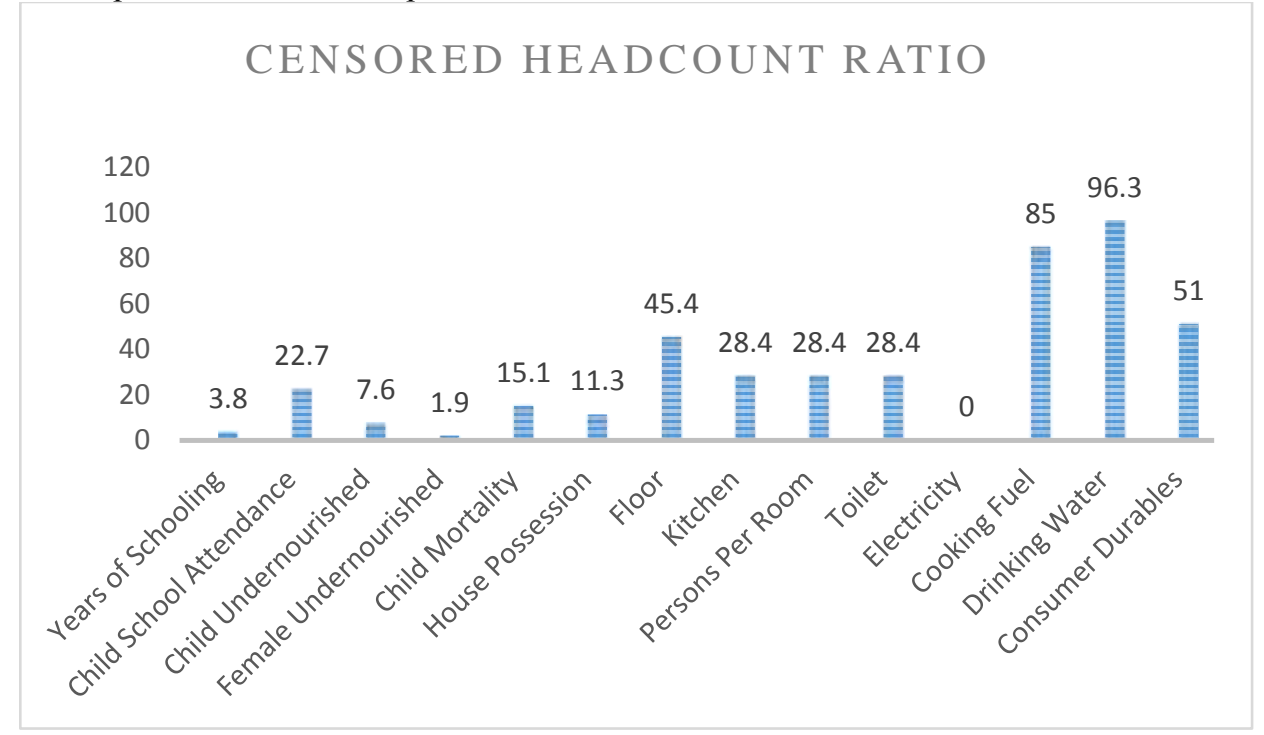

Figure 1: Censored Headcount Ratio

MPI poor and deprived in floor. The proportion of deprivations in separate kitchen, persons per room and improved sanitation are almost same (28.4\%). Regarding the house possession, $11.3 \%$ of the population do not have their own house and are MPI poor. Interestingly, there is no proportion of household deprived in electricity connection. In the health dimension, $15.1 \%$ of the household are MPI poor and deprived in the indicator of child mortality. 7.6\% and $1.9 \%$ represents MPI poor and deprivation in the 
indicator of child malnutrition and female malnutrition respectively. Moreover, in the education dimension, $22.7 \%$ represents the proportion of deprivation in school attendance and MPI poor. But, only $3.8 \%$ of the household are MPI poor and deprived in years of schooling.

Table3: Censored Headcount Ratio and Contribution of each indicator to MPI

\begin{tabular}{|c|c|c|c|}
\hline Dimensions & Indicators & $\begin{array}{c}\text { Censored Headcount } \\
\text { Ratio }\end{array}$ & Contributions to MPI \\
\hline \multirow{4}{*}{ Education } & Years of Schooling & 0.0378 & 0.03 \\
\cline { 2 - 4 } & Child School & & 0.18 \\
\hline \multirow{5}{*}{ Health } & Attendance & 0.2268 & 0.04 \\
\hline \multirow{5}{*}{ Living Standards } & Child Malnutrition & 0.0756 & 0.01 \\
\cline { 2 - 4 } & Female Malnutrition & 0.0189 & 0.08 \\
\cline { 2 - 4 } & Child Mortality & 0.1512 & 0.02 \\
\hline & House Possession & 0.1134 & 0.08 \\
\cline { 2 - 4 } & Floor & 0.4536 & 0.05 \\
\cline { 2 - 4 } & Kitchen & 0.2835 & 0.05 \\
\cline { 2 - 4 } & Persons Per Room & 0.2835 & 0.05 \\
\cline { 2 - 4 } & Toilet & 0.2835 & 0 \\
\cline { 2 - 4 } & Electricity & 0 & 0.15 \\
\cline { 2 - 4 } & Cooking Fuel & 0.8505 & 0.17 \\
\cline { 2 - 4 } & Drinking Water & 0.9639 & 0.09 \\
\cline { 2 - 4 } & Consumer Durables & 0.5103 & \\
\hline
\end{tabular}

Source: Authors' construction

Table 3 shows that the largest contribution to overall MPI of the village is deprivation in child school attendance $(18 \%)$, followed by safe drinking water $(17 \%)$ and cooking fuel $(15 \%)$. The least contribution is deprivation in electricity connection $(0 \%)$, followed by female malnutrition (1\%) and house possession $(2 \%)$. If the contributions of the three dimensions are analysed, it comes out as education (21\%), health $(13 \%)$ and living standard (66\%).

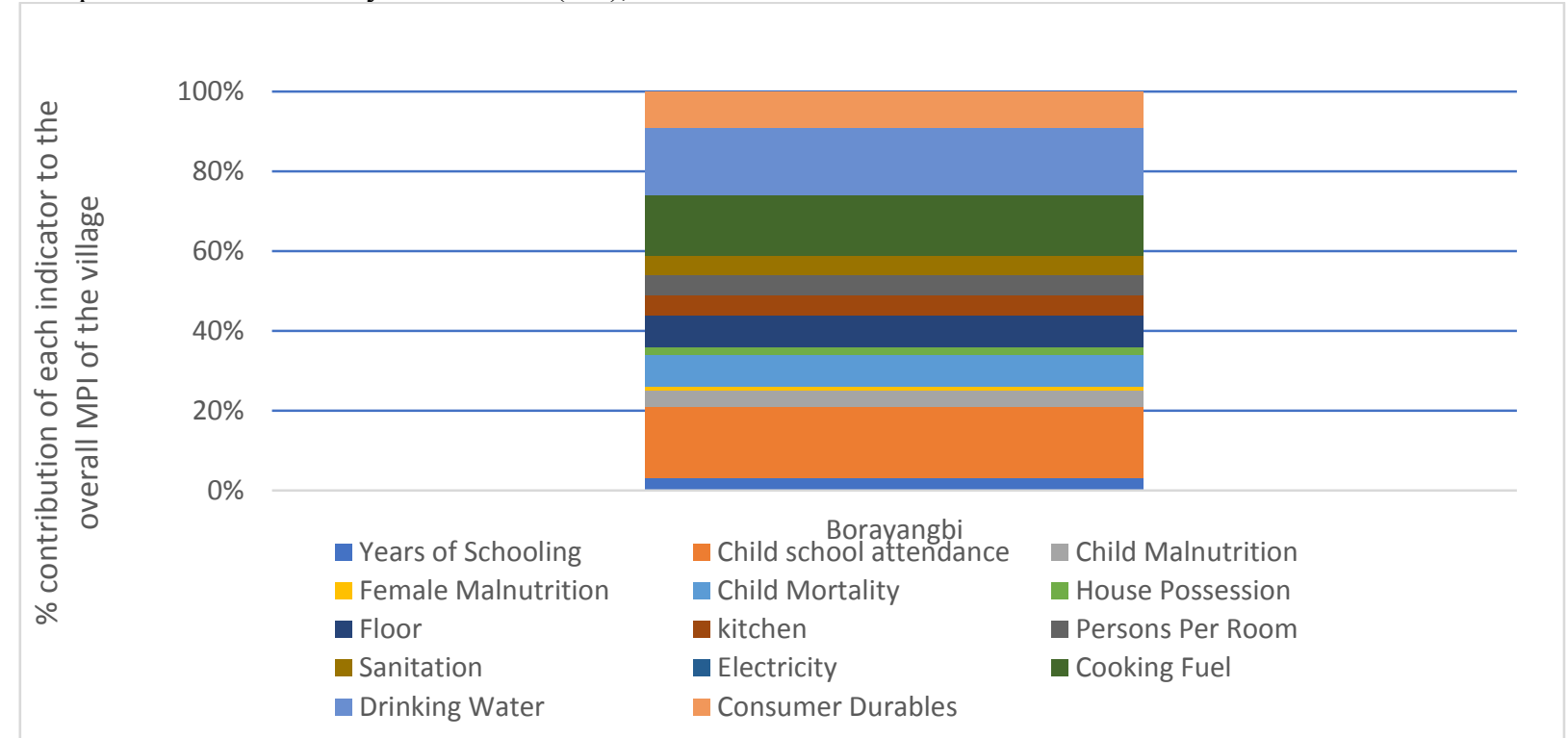

Figure 2: Percentage contribution of each indicator to the overall MPI of the village 


\section{Raw Headcount Ratio}

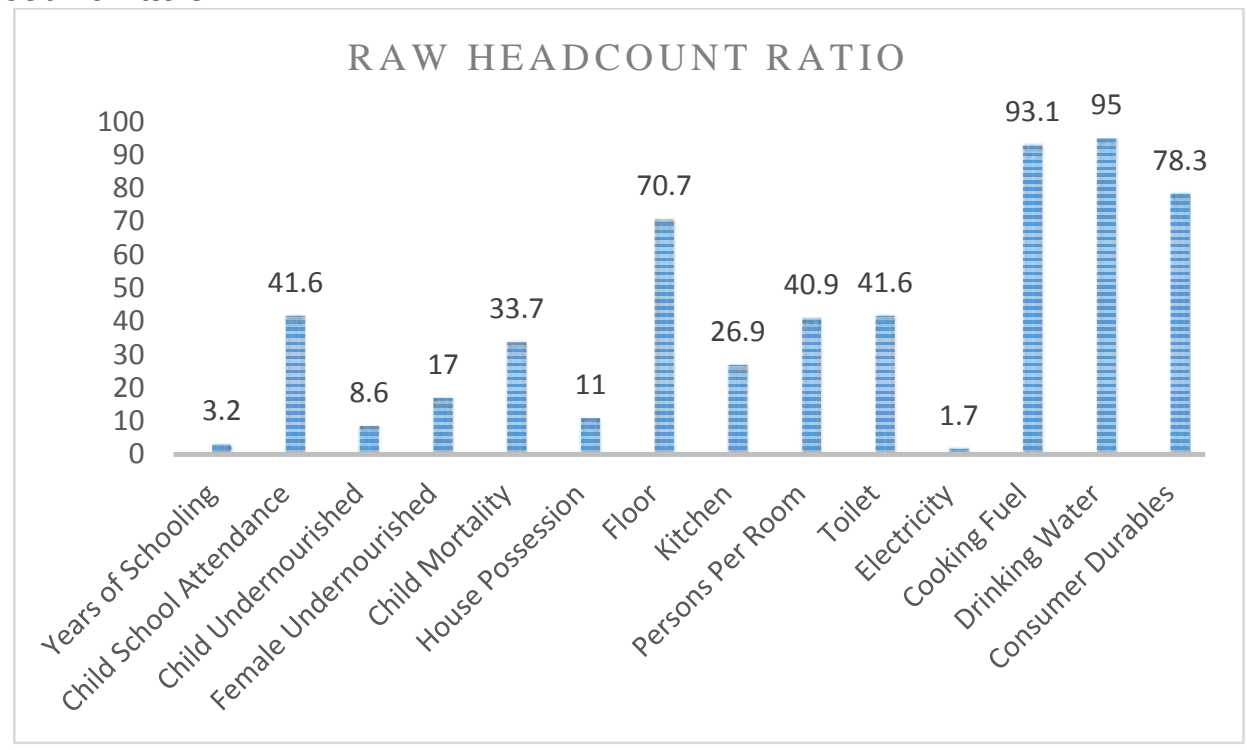

Figure 3: Raw Headcount Ratio

The figure above represents the raw headcount ratio of different indicators contributing to the overall MPI. It refers to all the deprivations of both poor and non-poor. Deprivation in drinking water $(95 \%)$ and cooking fuel $(93.1 \%)$ are the highest. Next is followed by deprivation in consumer durables $(78.3 \%)$. The least deprived is electricity connection (1.7\%).

\section{CONCLUSION}

From the field survey data, we estimate the Multidimensional Poverty Index (MPI) of Borayangbi village which comes out to 0.208 . It can be concluded that Pangals in the village are experiencing an acute poverty or deprivation. Around $49 \%$ of the population are deprived in various indicators. When it comes to the contribution of different dimensions to MPI, education accounts for $21 \%$, health for $13 \%$, and living standard for $66 \%$. As a result, the living standard contributes the most to the overall MPI. It indicates that villagers are lack of adequate facilities which are meant for decent standard of living. Within this dimension, lack of cooking fuel (17 percent) and access to clean drinking water (15 percent) are major deprivations. Government must make aware of the villagers about the various schemes and facilities provided by them regarding the supply of gas connection in minimum cost, so that the villagers have access to a reliable and safe cooking fuel. Safe drinking water must be provided with piped water which are absent in the village. In terms of education, the dropout rate for school-aged children is also very high. As a result, there is a significant lack of school attendance (18\%). This is something that the government and policymakers should look into. Regarding the education, the village needs a proper and well-established school which it currently lacks. Last but not least, in order to lift the people in the village especially the Pangals out of its acute poverty, the government, non-governmental organisations, and various stakeholders must come together and enact effective policy steps.

\section{REFERENCES}

1. Alkire, $S$ and Santos, M.E. (2010). Acute Multidimensional Poverty: A New Index for Developing Countries. OPHI working Paper No. 38 .

2. Alkire, S. (2002). Dimensions of human development. World Development, vol. 30(2): 180205.

3. Alkire, S. and Santos, M.E. (2010). Acute multidimensional poverty: A new index for developing countries. United Nations development programmed human development report office background paper, New York: UNDP.

4. Alkire, S. et al. (2011). Multidimensional poverty index - winter 2014/2015: Brief Methodological Note and Results Series. 2011; 1-13.

5. Alkire,S. and Housseini, B (2014). Multidimensional poverty in Sub-Saharan Africa: levels and trends. OPHI working paper No.81. Oxford department of international development. 2014.

6. Alkire,S. and Seth, S. ( 2015). Multidimensional poverty reduction in India between 1999 and 2006: Where and How? World Development: 93-108.

7. Banerjee, et.al. (2014). Multi-dimensional poverty index- a state level analysis of India. Working Paper No.5. CNRS (India).

8. Bidyadhar Dehury and Sanjay K. Mohanty (2015). Regional Estimates of Multidimensional Poverty in India. Economics: The Open-Access, OpenAssessment E-Journal, 9 (2015-36): 1-35. 
9. Dotter, C. and Klasen, S (2014). The multidimensional poverty index: achievements, conceptual and empirical issues, occasional paper. UNDP Human Development Report Office.

10. Global Multidimensional Poverty Index Report. (2018). OPHI.

11. Kumar, V. et al. (2015). Multidimensional poverty index: A state wise study of India in SARRC countries. International Journal of Enhanced Research in Educational Development.; 3(1), 1322.

12. Nath Bhattarai, Lekha (December 2014). Nature of Multidimensional Poverty incidence in Rural Nepal: Empirical Evidences from Bhalam VDC, Kaski. Economic Literature, Vol. XII (16-25).

13. National Statistics Bureau. (2014). Bhutan Multidimensional Poverty Index 2012 (Vol. 19). Available http://www.nsb.gov.bt/publication/files/pub0ll1571 bt.pdf

14. Nawar, A.-H. (2014). Multi-dimensional poverty index and tackling interlocking deprivations in the Arab States.

15. OPHI. (2017). Oxford poverty and human development initiative. 2017.

16. Philip, D. and Rayhan, M.I. (2004). Vulnerability and poverty: What are the causes and how are they related? Centre for development research, University of Bonn.

17. Sandip, Sarkar. Multidimensional Poverty in India: Insights from NSSO data. Indian Statistical Institute, Kolkata.

18. Sen, A. K. (1985). Commodities and Capabilities. Oxford University Press.

19. Socio Economic Survey of Meitei Pangal, 2004. Directorate of Economic and Statistic Department. Manipur.

20. Suppa, N. (2015). Towards a Multidimensional Poverty Index for Germany. OPHI Working Papers 98. 